\title{
Advances in Industrial Crystallization
}

\author{
Erik Temmel ${ }^{1,2}$ and Heike Lorenz ${ }^{2, * \text { CD }}$ \\ 1 Sulzer Chemtech Ltd., Gewerbestrasse 28, 4123 Allschwil, Switzerland; erik.temmel@sulzer.com \\ 2 Max Planck Institute for Dynamics of Complex Technical Systems, Sandtorstrasse 1, \\ 39106 Magdeburg, Germany \\ * Correspondence: lorenz@mpi-magdeburg.mpg.de
}

Received: 29 October 2020; Accepted: 31 October 2020; Published: 3 November 2020

Dear colleagues,

We are pleased to present the Crystals' Special Issue on "Advances in Industrial Crystallization". We are grateful for the large quantity of submitted manuscripts and we would like to thank all authors of the selected 15 publications for their efforts. In the following, a brief introduction describing the idea for creating this Special Issue and an overview of the related topics covered by the contributions is given.

As a general perspective from the industry, each process choice and design is individualized to each of the innumerous applications. For example, knowledge of basic thermodynamics yields the overall "map" for the crystallization process. The general solid-liquid equilibrium (SLE) type defines the separability of a mixture, depending on the operation conditions (i.e., composition, temperature, etc.) and determines the route to solidify the demanded solid-state form. Together with the kinetics of mass transfer and crystallization, which give insights into the expected crystal size distribution and shape development, an educated evaluation of various processes is feasible [1-5].

A decision between the reasonable options is taken afterward, based on the expected process of key performance indicators or constraints related to the specific application. For expensive fine chemicals, like enantiomers and other APIs, product purity and yield are commonly the focus, while for bulk chemicals, like inorganic salts or monomers (e.g., acrylic acid), productivity and process simplicity is mostly decisive. Subsequently, first lab-scale trials are usually conducted to evaluate the process choice and confirm the initial expectations. Suitable upscaling strategies are applied, afterward, to "level" the process up to the final plant, which can have capacities between a few kilograms or several hundred thousand tons per year. A careful monitoring of the critical parameters, like the liquid phase composition and temperature, but also the crystal shape and size distribution, exploiting suitable measurement techniques, is crucial at this stage of process development [6].

However, mostly empirical upscaling strategies exist in industry today and the above-mentioned detailed fundamental information are commonly not available and cannot be measured in the typical time of an industrial project. Hence, industry is inevitably dependent on academic research, which tirelessly helps to clarify the required essential issues.

Reflecting this successful relationship, all together 15 publications are summarized in this Special Issue. They comprise several contemporary aspects of crystallization and simultaneously give a comprehensive overview of industrially relevant topics in the field. The main subjects covered include (i) from fundamentals towards crystallization processes, (ii) crystal shape development, (iii) measurement techniques, (iv) continuous crystallization, (v) process intensification, (vi) melt crystallization, and (vii) nanoparticles in crystallization. In the following we briefly introduce the respective papers.

i. From fundamentals towards crystallization processes: As stated above, sophisticated crystallization process design relies on fundamentals like the present phase equilibria (e.g., 
solid-liquid, solid-solid) and the prevailing crystallization kinetics (like nucleation, growth, agglomeration, and breakage) [3,7-13]. The diversity of the individual properties in the solid state $[9,12]$ or the solidification process [10] of different products is one major challenge for each process engineer. Hence, continuously novel processes [11,13] and process combinations [10] are discovered to deal with these various issues to fulfill the desired task, like product purity or productivity enhancement. The materials studied from the authors comprise biologically active components or their precursors as amino acids, curcumin from a plant extract, or a particular chiral dimethylphenyl glycerol ether $[9,11,12]$. The application of specific antiscalants to inhibit gypsum scaling in $\mathrm{RO}$ desalination, and utilization of freeze concentration for recycling of an ionic liquid from its aqueous solution are introduced in articles $[10,13]$.

ii. Beside purity and solid-state form, the crystal size distribution and the crystal shape are often target properties of a product and also decide on the overall process performance [4,5]. Although the crystal morphology of a particular compound is primarily determined by its crystal lattice, the individual growth rates of the different crystallographic faces can lead to alternative crystal geometries. The latter might be caused by lattice defects at the crystal surface and crystallization conditions like temperature, supersaturation, impurities present, stirrer energy introduced, and hydrodynamic conditions in general $[2,4,5,14]$. Hence, there is a need for prediction or empirical study of crystal shape development, an issue that is considered in the Special Issue articles [15-17]. It can be shown for numerous substances that the crystal environment is decisive for the morphology, after the process [15], but the fundamental mechanisms [16] are still not completely clarified and there is a great demand for predictive tools [17] for the process design.

iii. In this connection, sophisticated measurement techniques are of particular importance $[5,6,18]$. To date, there is still a need for suitable measurement techniques to efficiently study and control crystallization processes. New methods for monitoring the process at the point of crystal formation (i.e., in situ), shed light on the evolution of the crystal size distribution [19] or the solid-state formation [20], for example. In [19], the authors introduce a new inline probe for image-based measurement of crystal size distribution, which is also applicable at larger scales. Whereas, in [20], equipment for the in situ small-scale determination of the crystal structure on the example of lysozyme is developed.

iv. Continuous crystallization as a common operation mode for most bulk chemical manufacturing processes has recently gained much interest from the pharmaceutical industry, and is thus, again focus of academic research [4,18,21-24]. Even though the basics were developed until the 80 s, there is still a great need for upscaling procedures [22], general process development [23], and new ideas for the efficient upstream and downstream combination [24]. The examples studied cover a broad range of applications as an industrially relevant fine chemical produced in a Draft Tube Baffled (DTB) crystallizer, at targeted particle-related properties [22], a continuous fine chemical enantiomer separation in coupled fluidized bed crystallizers [23], and the continuous synthesis of a chiral drug intermediate via an integrated biocatalysis-crystallization concept [24].

v. A novel field of interest is related to process intensification by integration of different unit operations, including crystallization $[10,18,23,24]$. The related Special Issue contributions demonstrate that combining crystallization and crystal size classification in one apparatus can lead to highly efficient processes that still meet the demanding purity requirements for pure enantiomers [23], and that combination with membrane concentration [10] can give rise to completely new fields of research. Additionally, the integration of a biocatalytic reaction with crystallization to overcome unfavorable chemical reaction equilibria [24] has attracted much interest, lately.

vi. Even though the focus of this Special Issue is mainly crystallization from solution, the ongoing activities in the field of industrial melt crystallization $[4,5,18,25]$ are represented as well $[13,17]$. Especially, in the common domains of freeze crystallization $[5,13,18]$ and metallurgy [17], 
new application fields are discovered as, for example, the recycling of ionic liquids [13], and novel, simulation tools are applied to elucidate the basic mechanisms of solid formation [17].

vii. Beside the purification or separation of enantiomers, fine chemicals or multi-component mixtures, where the isolation of a pure target product is of interest [11,12,23], the specific production of solids with defined characteristics is the main task for nanoparticles [15,26-29]. In the recent past, they gained increasing interest in industry and also in medical applications, due to their beneficial properties, which could be individualized for a specific duty [26,27]. The examples included in the Special Issue refer to new applications like capacitor energy-storage [28] and composite materials utilizing cellulose nanocrystals to reinforce biodegradable PBS polymers [29] as well as efficient catalysts in the cyanoethylation of methanol [15].

The range of fundamental and application-oriented aspects addressed in the present Special Issue on Advances in Industrial Crystallization highlights the progress and future directions of research in our field. We hope you will enjoy and appreciate the authors contributions, which might inspire new and fruitful projects.

Heike Lorenz and Erik Temmel

Magdeburg/Germany and Allschwil/Switzerland, October 2020

\section{References}

1. Tung, H.-H.; Paul, E.L.; Midler, M.; McCauley, J.A. Crystallization of Organic Compounds, 1st ed.; John Wiley \& Sons, Inc.: Hoboken, NJ, USA, 2009.

2. Myerson, A.S. Handbook of Industrial Crystallization, 2nd ed.; Butterworth-Heinemann: Boston, MA, USA, 2001.

3. Nývlt, J.; Söhnel, O.; Matuchová, M.; Boul, M. The Kinetics of Industrial Crystallization; Elsevier Science Ltd.: Amsterdam, The Netherlands, 1985.

4. Beckmann, W. Crystallization-Basic Concepts and Industrial Applications, 1st ed.; Wiley-VCH: Weinheim, Germany, 2013.

5. Lewis, A.; Seckler, M.; Kramer, H.; van Rosmalen, G. Industrial Crystallization-Fundamentals and Applications; Cambridge University Press: Cambridge, UK, 2015.

6. Chianese, A.; Kramer, H.J.M. Industrial Crystallization Process Monitoring and Control; Wiley-VCH: Weinheim, Germany, 2012.

7. Mullin, J.W. Crystallization, 4th ed.; Butterworth-Heinemann: Oxford, UK, 2001.

8. Lorenz, H. Solubility and Solution Equilibria in Crystallization. In Crystallization, 1st ed.; Wiley-VCH: Weinheim, Germany, 2013; pp. 35-74.

9. Kotelnikova, E.; Sadovnichii, R.; Kryuchkova, L.; Lorenz, H. Limits of Solid Solutions and Thermal Deformations in the L-Alanine-L-Serine Amino Acid System. Crystals 2020, 10, 618. [CrossRef]

10. Oshchepkov, M.; Golovesov, V.; Ryabova, A.; Redchuk, A.; Tkachenko, S.; Pervov, A.; Popov, K. Gypsum Crystallization during Reverse Osmosis Desalination of Water with High Sulfate Content in Presence of a Novel Fluorescent-Tagged Polyacrylate. Crystals 2020, 10, 309. [CrossRef]

11. Horosanskaia, E.; Yuan, L.; Seidel-Morgenstern, A.; Lorenz, H. Purification of Curcumin from Ternary Extract-Similar Mixtures of Curcuminoids in a Single Crystallization Step. Crystals 2020, 10, 206. [CrossRef]

12. Bredikhin, A.A.; Zakharychev, D.V.; Bredikhina, Z.A.; Kurenkov, A.V.; Samigullina, A.I.; Gubaidullin, A. Stereoselective Crystallization of Chiral 3,4-Dimethylphenyl Glycerol Ether Complicated by Plurality of Crystalline Modifications. Crystals 2020, 10, 201. [CrossRef]

13. Osmanbegovic, N.; Yuan, L.; Lorenz, H.; Louhi-Kultanen, M. Freeze Concentration of Aqueous [DBNH][OAc] Ionic Liquid Solution. Crystals 2020, 10, 147. [CrossRef]

14. Nývlt, J.; Ulrich, J. Admixtures in Crystallization, 1st ed.; Wiley-VCH: Weinheim, Germany, 1995.

15. Cheong, Y.-W.; Wong, K.-L.; Ooi, B.; Ling, T.C.; Khoerunnisa, F.; Ng, E.-P. Effects of Synthesis Parameters on Crystallization Behavior of K-MER Zeolite and Its Morphological Properties on Catalytic Cyanoethylation Reaction. Crystals 2020, 10, 64. [CrossRef] 
16. Zhu, D.; Zhang, S.; Cui, P.; Wang, C.; Dai, J.; Zhou, L.; Huang, Y.; Hou, B.; Hao, H.; Zhou, L.; et al. Solvent Effects on Catechol Crystal Habits and Aspect Ratios: A Combination of Experiments and Molecular Dynamics Simulation Study. Crystals 2020, 10, 316. [CrossRef]

17. Bai, Y.; Wang, Y.; Zhang, S.; Wang, Q.; Li, R. Numerical Model Study of Multiple Dendrite Motion Behavior in Melt Based on LBM-CA Method. Crystals 2020, 10, 70. [CrossRef]

18. Yazdanpanah, N.; Nagy, Z.K. (Eds.) The Handbook of Continuous Crystallization, 1st ed.; Royal Society of Chemistry: Cambridge, UK, 2020.

19. Wirz, D.; Hofmann, M.; Lorenz, H.; Bart, H.-J.; Seidel-Morgenstern, A.; Temmel, E. A Novel Shadowgraphic Inline Measurement Technique for Image-Based Crystal Size Distribution Analysis. Crystals 2020, 10, 740. [CrossRef]

20. Liang, M.; Wang, Z.; Wu, H.; Yu, L.; Sun, B.; Zhou, H.; Yu, F.; Wang, Q.; He, J. Microplates for Crystal Growth and in situ Data Collection at a Synchrotron Beamline. Crystals 2020, 10, 798. [CrossRef]

21. Temmel, E. Design of Continuous Crystallization Processes. Ph.D. Thesis, Otto von Guericke University, Magdeburg, Germany, 2016.

22. Melches, C.; Plate, H.; Schürhoff, J.; Buchfink, R. The Steps from Batchwise to Continuous Crystallization for a Fine Chemical: A Case Study. Crystals 2020, 10, 542. [CrossRef]

23. Temmel, E.; Gänsch, J.; Seidel-Morgenstern, A.; Lorenz, H. Systematic Investigations on Continuous Fluidized Bed Crystallization for Chiral Separation. Crystals 2020, 10, 394. [CrossRef]

24. Hülsewede, D.; Temmel, E.; Kumm, P.; Von Langermann, J. Concept Study for an Integrated Reactor-Crystallizer Process for the Continuous Biocatalytic Synthesis of (S)-1-(3-Methoxyphenyl)ethylamine. Crystals 2020, 10, 345. [CrossRef]

25. Ulrich, J.; Glade, H. Melt Crystallization: Fundamentals, Equipment and Applications, 1st ed.; Shaker Verlag: Aachen, Germany, 2003.

26. Bhushan, B. Springer Handbook of Nanotechnology, 4th ed.; Springer: Berlin, Germany, 2017.

27. Nivethaa, E.A.K.; Martin, C.A.; Frank-Kamenetskaya, O.V.; Kalkura, S.N. Chitosan and Chitosan Based Nanocomposites for Applications as a Drug Delivery Carrier A Review. In Processes and Phenomena on the Boundary Between Biogenic and Abiogenic Nature. Lecture Notes in Earth System Sciences; Frank-Kamenetskaya, O., Vlasov, D., Panova, E., Lessovaia, S., Eds.; Springer: Cham, Switzerland, 2019; pp. 23-37. [CrossRef]

28. Li, M.; Gu, L.; Li, T.; Hao, S.; Tan, F.; Chen, D.; Zhu, D.-L.; Xu, Y.; Sun, C.; Yang, Z. TiO2-Seeded Hydrothermal Growth of Spherical BaTiO3 Nanocrystals for Capacitor Energy-Storage Application. Crystals 2020, 10, 202. [CrossRef]

29. Abushammala, H.; Mao, J. Impact of the Surface Properties of Cellulose Nanocrystals on the Crystallization Kinetics of Poly(Butylene Succinate). Crystals 2020, 10, 196. [CrossRef]

Publisher's Note: MDPI stays neutral with regard to jurisdictional claims in published maps and institutional affiliations.

(C) 2020 by the authors. Licensee MDPI, Basel, Switzerland. This article is an open access article distributed under the terms and conditions of the Creative Commons Attribution (CC BY) license (http://creativecommons.org/licenses/by/4.0/). 